\title{
Clavien Classification of Complication of Surgery in Emergency Laparotomy - A Study of 40 Cases in Combined Military Hospitals
}

\author{
Hasan $M M^{1}$, Matin $M A^{2}$, Jafran $S S^{3}$, Laila $S Z^{4}$, Mamun $M M H^{5}$
}

\begin{abstract}
Introduction: Although quality assessment is gaining increasing attention, there is still no consensus on how to define and grade postoperative complications. This shortcoming hampers comparison of outcome data among different centers, therapies and over time.
\end{abstract}

Objective: Objective of the study was to assess the Clavien classification of surgical complications of patients who underwent emergency laparotomy.

Materials and Methods: The classification was tested on 40 patients who underwent emergency laparotomy in various Combined Military Hospitals $(\mathrm{CMH})$ over a period of 09 years. Data recorded including demographics, clinical presentations, operating techniques, incision, post-operative complications and the duration of hospital stay.

Results: Out of the total 40 patients, $28(70 \%)$ were male and $12(30 \%)$ female. Male: Female ratio was 2.33:1. A total of $29(72.50 \%)$ patients experienced postoperative complications. More than one complications occurred in $14(35 \%)$ patients. There were $13(32.50 \%)$ patients in the Clavien grade-I category, 09(22.50\%) patients were classified as grade-II and grade-IIla, $05(12.50 \%)$ patients had IIIb complications, grade-IVb and $V$ complications occurred in $03(07.50 \%)$ patients each. The mean length of hospital stay was 15.28 days.

Conclusion: This classification seems to be applicable in most parts of the world and may even be used by surgeons who are less experienced. In addition, standardization of postoperative care is essential to minimize postoperative complications.
Key-words: Clavien classification, surgical complications, emergency laparotomy.

\section{Introduction}

Growing demand for health care, rising costs, constrained resources, and evidence of variations in clinical practice have triggered interest in measuring and improving the quality of health care delivery ${ }^{1}$. Emergency laparotomy is a common high-risk surgical procedure, but with few outcome data and few data on postoperative care ${ }^{2}$. The decision on whether to operate on a sick person with an intra-abdominal emergency is one of the most difficult in general surgery. Surgery may not be advised if the chance of success is slight and the risk of causing a fatal outcome is considered greater by operating. Scoring systems can provide objectivity and mortality prediction enabling communication and understanding of severity of illness. Incorporating subjective factors within scoring systems can allow clinicians to apply their experience and understanding of the situation to an individual but are not reproducible ${ }^{3}$. Many publications describe the use of post-operative scoring systems such as POSSUM (Physiological and Operative Severity Score for the enumeration of Mortality and Morbidity) to compare predicted and observed outcomes ${ }^{4}$. In 1992. Clavien et al proposed a classification of complications ${ }^{5}$, which is based on the type of therapy needed to correct the complication. This Classification appears reliable and may represent a compelling tool for quality assessment in surgery ${ }^{1,6}$. The aim of this study was to test this classification on patients who underwent emergency laparotomy and to assess the reproducibility and acceptability of the classification through an international survey as well as to find out the measures to prevent those complications.

1. Lt Col Md Mahboob Hasan, MBBS, FCPS, Diploma (Hepatobiliary Surgery), Classified Specialist in Surgery and Hepatobiliary Surgeon, CMH Dhaka 2. Brig Gen Md Abdul Matin, MBBS, FCPS, Professor and Head, Department of Surgery, AFMC, Dhaka 3. Lt Col Sardar Shahnabi Jafran, MBBS, FCPS, Classified Specialist in Surgery, CMH Saidpur 4. Maj Syeda Zeenat Laila, MBBS, DCH, FCPS, Classified Specialist in Paediatrics, OKP-5, Kuwait 5. Dr Md Monjur Hasan Mamun, MBBS, Medical Officer (Surgery), Dhaka Medical College Hospital, Dhaka. 


\section{Materials and Methods}

This observational study had been carried out in Combined Military Hospital (CMH) Dhaka, Main Dressing Station (MDS) 5 Field Ambulance, CMH Momenshahi and CMH Ghatail during the period of August 2002 to August 2011. A total of 40 patients underwent emergency laparotomy were studied. Patients were included if they underwent a midline exploration of the abdomen classified as 'urgent' defined as needing surgery within hours of diagnosis; or 'emergency', requiring surgery within minutes of diagnosis. Patients undergoing a 're-look laparotomy' were excluded, as were patients undergoing an emergency appendicectomy. No patient was excluded with the ground of obesity or other co-morbid diseases (diabetes, bronchial asthma, hypertention etc.).

A detailed history was taken from the patients. Data were recorded including demographics, clinical presentations, preoperative laboratory investigation reports, operating techniques, operating time, incision, post-operative complications and the duration of hospital stay. All the patients were followed up regularly during their stay in the Hospital and as out patient.

\section{Results}

The youngest patient of this series was 11 years and oldest was of 85 years. Male were $28(70 \%)$ and Female $12(30 \%)$; Male: Female $=2.33: 1($ Table-I).

Table-I: Distribution of Patients according to age and sex $(n=40)$

\begin{tabular}{|l|c|c|c|c|c|c|c|c|}
\hline $\begin{array}{l}\text { Age } \\
\text { (Years) }\end{array}$ & $\mathbf{< 2 0}$ & $\mathbf{2 0 - 3 0}$ & $\mathbf{3 1 - 4 0}$ & $\mathbf{4 1 - 5 0}$ & $\mathbf{5 1}$ years and above & Total & $\mathbf{\%}$ & $\mathbf{M}: \mathbf{F}$ \\
\hline Male & 02 & 03 & 09 & 10 & 04 & 28 & 70 & \\
\hline Female & 01 & 02 & 03 & 04 & 02 & 12 & 30 & \\
\hline Total & 03 & 05 & 12 & 14 & 06 & 40 & 100 & $2.63: 1$ \\
\hline
\end{tabular}

Maximum patients (11) were operated for intestinal obstruction, then perforation of hollow viscus. Only one patient underwent laparotomy for acute pancreatitis with 36 weeks pregnancy with foetal distress (Table-II). Total 08 patients required peri-operative blood transfusion.

Table-II: Distribution of Patients according to reasons of emergency laparotomy $(n=40)$

\begin{tabular}{|l|c|c|}
\hline Cause of surgery & Number of patients & Percentage \\
\hline Perforation of hollow viscus & 10 & 25.00 \\
\hline Intestinal obstruction & 11 & 27.50 \\
\hline Strangulated hernia & 04 & 10.00 \\
\hline Burst appendix & 03 & 07.50 \\
\hline Stab injury & 03 & 07.50 \\
\hline Gun shot / blast injury & 05 & 12.50 \\
\hline Blunt abdominal trauma & 03 & 07.50 \\
\hline Acute pancreatitis with 36 weeks pregnancy & 01 & 02.50 \\
\hline
\end{tabular}

Nausea and vomiting were the most frequent complications. No complication observed in $11(27.50 \%)$ patients. More than one complications occurred in $14(35 \%)$ patients. Maximum patients $(32.50 \%)$ developed Grade-I complications, then Grade-II (22.50\%) and Grade-Illa (22.50\%) complications. Total $3(07.50)$ patients died (2 for liver injury due to blunt abdominal trauma and 1 for anastomotic leackage following previous surgery for colonic malignancy) (Table-III) and (Table-IV) and all other were back to their normal life and work without any significant problem during the period of follow up. 
Table-III : Distribution of Patients according to list of complications $(n=40)$

\begin{tabular}{|l|c|c|}
\hline Complications & Number of patients & Percentage \\
\hline Nausea and vomiting & 13 & 32.50 \\
\hline Bleeding (Post-operative) & 01 & 02.50 \\
\hline Cardiac complications & 03 & 07.50 \\
\hline \multicolumn{1}{|c|}{ Arrhythmia } & 02 & 05.00 \\
\hline \multicolumn{1}{|c|}{ Heart failure } & 01 & 02.50 \\
\hline Abdominal collection & 02 & 05.00 \\
\hline Surgical Site Infection (SSI) & 08 & 20.00 \\
\hline Wound dehiscence & 02 & 05.00 \\
\hline GI bleeding & 02 & 05.00 \\
\hline GI fistula & 01 & 02.50 \\
\hline Prolonged ileus (TPN) & 02 & 05.00 \\
\hline Anastomotic leak & 01 & 02.50 \\
\hline Multiple organ failure & 03 & 07.50 \\
\hline Respiratory complications & 05 & 12.50 \\
\hline Death & 03 & 07.50 \\
\hline
\end{tabular}

Table-IV: Distribution of Patients according to grade of complications $(n=40)$

\begin{tabular}{|c|c|c|}
\hline Gradings & Number of patients & Percentage \\
\hline Grade-I & 13 & 32.50 \\
\hline Grade-II & 09 & 22.50 \\
\hline Grade-III & 14 & 35.00 \\
\hline a) & 09 & 22.50 \\
\hline b) & 05 & 12.50 \\
\hline Grade-IV & 03 & 07.50 \\
\hline a) & 00 & 00.00 \\
\hline b) & 03 & 07.50 \\
\hline Grade- $V$ & 03 & 07.50 \\
\hline
\end{tabular}

Median length of hospitalization in patients without complication was 9.36 days. Hospital stay in patients with complications was, respectively, 10 days when patients developed Grade-I complications only, 11.17 days in those with Grade-II, 26.67 days in presence of Grade-IIla, 31.20 days in Grade-IIlb and 49.00 days in Grade-IVb complications. Length of hospitalization of patients who died due to a complication (Grade-V) was 2.33 days. Average hospital stay was 15.28 days.

\section{Discussion}

The rising cost of health care is given increasingly importance worldwide. A major factor affecting hospital cost is complications following surgery ${ }^{7,8}$. The absence of consensus within the surgical community on the best way to report surgical complications has hampered proper evaluation of the surgeon's work and possibly progress in the surgical field ${ }^{9}$. General surgical emergency admissions are the largest group of all surgical admissions to UK hospitals ${ }^{10}$ and account for a large percentage of all surgical deaths ${ }^{11}$. Clavien Classification of Surgical Complications $^{1,12}$ is a useful tool for those interested in surgical audit or clinical investigation. It has subsequently been used by us for outcome assessment.

Grade-I: Any deviation from the normal postoperative course without the need for pharmacological treatment or surgical, endoscopic, and radiological interventions.

Grade-II: Requiring pharmacological treatment with drug other than such allowed for Grade-I complications. 
Grade-III: Requiring surgical, endoscopic or radiological intervention.

Grade-IIla: Intervention not under general anaesthesia.

Grade-IIIb: Intervention under general anaesthesia.

Grade-IV: Life-threatening complication.

Grade-IVa: Single organ dysfunction.

Grade-IVb: Multiorgan dysfunction.

Grade-V: Death of a patient.

If the patients suffer from a complication at the time of discharge, the suffix "d" (for 'disability') is added to the respective grade of complication. This label indicates the need for a follow-up to fully evaluate the complication ${ }^{13}$. Compared with elective surgery, emergency abdominal surgery is associated with a higher risk of morbidity and mortality, especially in patients over the age of 65 and where $50 \%$ of these patients have significant associated comorbidities ${ }^{14}$.

Exploratory laparotomy is used to visualize and examine the structures inside of the abdominal cavity may be recommended for a patient who has abdominal pain of unknown origin or who has sustained an injury to the abdomen. Injuries may occur as a result of blunt trauma (e.g., road traffic accident) or penetrating trauma (e.g., stab or gunshot wound) $)^{15,16}$. Patients over 80 years of age are more likely to present for emergency surgery than for elective surgery ${ }^{17}$. In this study maximum patients were within 41 to 50 years of age. As this study have included some traumatic cases.

In order to minimize or even avoid complications it is crucial to know the risk factors and strategies to prevent, treat or reduce intra and postoperative complications $^{18}$.

In multi-variant analyses, age on its own has been shown to be a poor predictor of mortality, morbidity or length of stay in hospital ${ }^{19}$. A fit elderly person should not be refused an emergency operation because of their age alone. Although the American Society of Anaesthesiologists (ASA) classification of fitness for surgery was not devised as a risk prediction score, it has been used in this way, both on its own, and in conjunction with other patient or operative variables such as age, sex, urgency of surgery or APACHE-II (Acute Physiology and Chronic Health Evaluation II) score ${ }^{4}$.

Initially, it was thought that obese patients have a higher complication rate especially in the case of a laparoscopic approach. Some groups reported longer operating time, prolonged hospital stay and higher intraoperative complication rates ${ }^{20}$. Patients with a BMI over $25 \mathrm{~kg} / \mathrm{m}^{2}$ have a higher risk for incisional hernias and have an increased rate of surgical site infection $^{21,22}$. Malnutrition has been recognized as an independent risk factor of perioperative morbidity for many decades, but there is currently no standardized definition of malnutrition ${ }^{23,24}$. The postoperative recovery of all surgical patients can be improved by an early start of enteric nutrition postoperatively. When the enteric administration of food is not possible, total parenteral nutrition can be given to bridge a long period without food ${ }^{25}$. Perioperative anemia is associated with increased postoperative complications and mortality ${ }^{26}$. In a recent study the 30 days mortality and cardiac event rates increased, with either positive or negative deviations from normal hematocrit levels ${ }^{27}$. in this study 08 patients required peri-operative blood transfusion.

The choice of incision for laparotomy depends on the area that needs to be exposed, the elective or emergency nature of the operation and the personal preference. Some authors report abdominal or neural dysfunction after transverse access because of nerve, muscle or vessel interruption ${ }^{28}$. A midline incision is still the incision of choice in conditions that require rapid intra-abdominal entry or where the preoperative diagnosis is uncertain, as it is quicker and can easily be extended ${ }^{29}$. Many studies showed that prolonged operating time correlated with higher intra and postoperative complications ${ }^{18}$.

Good postoperative pain control is an important part of adequate postoperative care. Inadequate postoperative pain relief may delay recovery, lead to a prolonged hospital stay and increase medical $\operatorname{costs}^{30}$. The improved outcome may be because of a better pain control with epidural analgesia, with subsequently enhanced respiratory function ${ }^{31}$. Early enteral nutrition is associated with reduced mortality, 
though the mechanism is not clear $^{32}$. When the enteric administration of food turns out to be impossible, total parenteral nutrition can be given to bridge a long period without food ${ }^{25}$.

The most frequent postoperative surgical complications are surgical site infection (SSI), anastomotic leakage, intra-abdominal abscess, ileus and bleeding. Some studies showed that perioperative oxygen supply and preoperative immunonutrition decreased surgical site infection signi-ficantly ${ }^{33,34}$. Most studies favour one to three intravenous doses of a second generation cephalosporine with or without metronidazole with the first dose being administered before skin incision ${ }^{35}$. Abdominal wound dehiscence remains a major cause of morbidity following any laparotomy whether elective or emergency. The burst abdomen is associated with high morbidity of up to $40 \%$ and mortality of up to $18 \%$ in elderly or malnourished patients in whom a burst represents a final additional insult to their already stressed physiology ${ }^{36}$. Interrupted whole layer closure during performance of emergency laparotomy for peritonitis patient is very effective for preventing postoperative wound- related complication and it is as effective as layered suture for preventing delayed ventral hernia in the long-term ${ }^{37}$. Here $08(20.00 \%)$ patients developed SSI and 02 (05.00\%) had burst abdomen which were managed subsequently.

Anastomotic leakage is the most serious complication specific to intestinal surgery and ranges from $2.9 \%$ to as high as $15.3 \%$. In general, the leakage rate for intraperitoneal anastomoses is significantly lower than for extraperitoneal anastomoses. ${ }^{18}$. Some leaks presents in a dramatic fashion early in the postoperative period, leaving little doubt about the diagnosis. However, many others present in a far more subtle fashion, often relatively late in the postoperative period, and can be difficult to distinguish from other postoperative infectious complications $^{38}$. There seems to be no significant difference in leakage when comparing a handsewn and a stapled technique regardless of the level of anastomosis $^{39}$. Only one patient $(02.50 \%)$ developed anastomotic leak who had a thyphoid ulcer perforation. Abscess formation and bleeding, organ injury and fistula formation at 'on demand' relaparotomies are well-known complications after surgery for intraabdominal sepsis associated with fibrinous adhesions ${ }^{40}$. Postoperative ileus has long been considered an an inevitable consequence of gastrointestinal surgery. It prolongs hospital stay, increases morbidity, and adds to treatment costs. The operating time and intraoperative blood loss are independent risk factors for a postoperative ileus ${ }^{41}$. Two patients $(5.00 \%)$ in this study developed prolonged illeus and improved with subsequent management.

\section{Conclusion}

The morbidity scale based on the therapeutic consequences of complications constitutes a simple, objective and reproducible approach for comprehensive surgical outcome assessment. This classification seems to be applicable in most parts of the world and may even be used by surgeons who are less experienced. The broad implementation of this classification into surgical literature may facilitate the evaluation and comparison of surgical outcomes among different surgeons, centers, and therapies. In addition, standardization of postoperative care is essential to minimize postoperative complications.

\section{References}

1. Dindo D, Demartines N, Clavien PA. Classification of surgical complications: a new proposal with evaluation in a cohort of 6336 patients and results of a survey. Ann Surg 2004; 240:205-13.

2. Clarke, Adrian; Murdoch, et al. Mortality and postoperative care after emergency laparotomy. European Journal of Anaesthesiology. January 2011; 28(1):16-9.

3. Chandra A, Mangam S, Marzouk D. A Review of Risk Scoring Systems Utilised in Patients Undergoing Gastrointestinal Surgery. Journal of Gastrointestinal Surgery 2009; 13(8):1529-38.

4. Thomas E Rix, Tom Bates. Pre-operative risk scores for the prediction of outcome in elderly people who require emergency surgery. World Journal of Emergency Surgery 2007; 2:16.

5. Clavien P, Sanabria J, Strasberg S: Proposed classification of complication of surgery with examples of utility in cholecystectomy. Surgery 1992; 111:518-26.

6. Clavien PA, Barkun J, de Oliveira ML, et al. The Clavien-Dindo classification of surgical complications: five-year experience. Ann Surg 2009; 250:187-96.

7. Pronovost P, Garrett E, Dorman T, et al. Variations of complication rates and opportunities for improvement in quality of care for patients having abdominal aortic surgery. Arch Surg 2001; 386:249-56.

8. Lang M, Niskanen M, Miettinen $\mathrm{P}$, et al. Outcome and resource utilization in gastrointestinal surgery. $\mathrm{Br} \mathrm{J}$ Surg 2001; 88:1006-14. 
9. Martin RC 2nd, Brennan MF, Jaques DP. Quality of complication reporting in the surgical literature. Ann Surg 2002; 235:803-13.

10. Association of Surgeons of Great Britain and Ireland. Emergency general surgery: the future. A consensus statement; June 2007. www.asgbi.co.uk

11. Pearse RM, Harrison DA, James $P$, et al. Identification and characterization of the high-risk surgical population in the United Kingdom. Crit Care 2006; 10:R81.

12. Tan KK, Quek TJL, Wong N, et al. Emergency surgery for perforated gastric malignancy: An institution's experience and review of the literature. J Gastrointest Oncol 2011; 2:13-8.

13. Andres A, Toso C, Moldovan B, et al. Complications of Elective Liver Resections in a Center With Low Mortality A Simple Score to Predict Morbidity. Arch Surg. Published online July 18, 2011. doi:10.1001/archsurg 2011.175.

14. Saleh M, Kahokehr A, Mahmoud M, et al. The Simple Prognostic Index (SPI)-A Pathophysiologic Prognostic Scoring Tool for Emergency Laparotomy. Journal of Surgical Research. October 2010; 163(2): e59-e65.

15. Marx, John A, et al. Rosen's Emergency Medicine. St. Louis, MO: Mosby, Inc 2002.

16. Hahn, David D, Steven R. Offerman, and James F. Holmes. "Clinical Importance of Intraperitoneal Fluid in Patients with Blunt Intra-abdominal Injury." American Journal of Emergency Medicine 20, no.7 (November 2002).

17. Turrentine FE, Wang $H$, Simpson VB, et al. Surgical risk factors, morbidity and mortality in elderly patients. $J$ Am Coll Surg 2006; 6:865-77.

18. Kirchhoff P, Clavien PA, Hahnloser D. Complications in colorectal surgery: risk factors and preventive strategies. Patient Safety in Surgery 2010; 4:5.

19. Arenal JJ, Bengoechea-Beeby M. Mortality associated with emergency abdominal surgery in the elderly. Can $\mathrm{J}$ Surg 2003; 46:111-6.

20. Pikarsky AJ, Saida Y, Yamaguchi T, et al. Is obesity a high-risk factor for laparoscopic colorectal surgery? Surg Endosc 2002; 16:855-8.

21. Hoer J, Lawong $G$, Klinge $U$, et al. Factors influencing the development of incisional hernia. A retrospective study of 2,983 laparotomy patients over a period of 10 years. Chirurg 2002; 73:474-80.

22. Smith RL, Bohl JK, McElearney ST, et al. Wound infection after elective colorectal resection. Ann Surg 2004; 239:599-605.

23. Wu GH, Liu ZH, Wu ZH et al. Perioperative artificial nutrition in malnourished gastrointestinal cancer patients. World J Gastroenterol 2006; 12:2441-4.
24. Schiesser M, Muller S, Kirchhoff $P$ et al. Assessment of a novel screening score for nutritional risk in predicting complications in gastro-intestinal surgery. Clin Nutr 2008; 27:565-70.

25. Garretsen MK, Melis GC, Richir MC et al. Perioperative nutrition. Ned Tijdschr Geneeskd 2006; 150:2745-9.

26. Dunne JR, Malone D, Tracy JK, et al. Perioperative anemia: an independent risk factor for infection, mortality, and resource utilization in surgery. J Surg Res 2002; $102: 237-44$

27. Wu WC, Schifftner TL, Henderson WG, et al. Preoperative hematocrit levels and postoperative outcomes in older patients undergoing noncardiac surgery. JAMA 2007; 297:2481-8

28. Israelsson LA, Cengiz Y. Letter 2: Randomized clinical trial of vertical or transverse laparotomy for abdominal aortic aneurysm repair. (Br J Surg 2005; 92:1208-11). Br J Surg 2006, 93:121-2.

29. Grantcharov TP, Rosenberg J. Vertical compared with transverse incisions in abdominal surgery. Eur J Surg 2001; 167:260-7.

30. Pöpping DM, Zahn PK, Van Aken HK, et al. Effectiveness and safety of postoperative pain management: a survey of 18925 consecutive patients between 1998 and 2006 (2nd revision): a database analysis of prospectively raised data. Br J Anaesth 2008; 101(6): 832-40.

31. Daniel M, Elia N, Marret E, et al. Protective Effects of Epidural Analgesia on Pulmonary Complications After Abdominal and Thoracic Surgery A Meta-Analysis. Arch Surg 2008; 143(10):990-9.

32. Stephen J. Lewis, Henning K. Andersen, Steve Thomas. Early Enteral Nutrition Within $24 \mathrm{~h}$ of Intestinal Surgery Versus Later Commencement of Feeding. A Systematic review and Meta-analysis. Journal of Gastrointestinal Surgery 2009; 13(3):569-75.

33. Brasel K, McRitchie D, Dellinger P. Canadian Association of General Surgeons and American College of Surgeons Evidence Based Reviews in Surgery. 21: the risk of surgical site infection is reduced with perioperative oxygen. Can J Surg 2007; 50:214-6.

34. Horie H, Okada M, Kojima M, et al. Favorable effects of preoperative enteral immunonutrition on a surgical site infection in patients with colorectal cancer without malnutrition. Surg Today 2006; 36:1063-8.

35. Fujita S, Saito N, Yamada T, et al. Randomized, multicenter trial of antibiotic prophylaxis in elective colorectal surgery: single dose vs 3 doses of a second-generation cephalosporin without metronidazole and oral antibiotics. Arch Surg 2007; 142:657-61. 
36. Srivastava A, Roy S, Sahay KB, et al. Prevention of burst abdominal wound by a new technique: A randomized trial comparing continuous versus interrupted $\mathrm{X}$-suture. Indian Journal of Surgery, Jan-Feb, 2004; 66(1):19-27.

37. Hyun SY, Kim YJ, Cho SW, et al. Prevention of the Abdominal Wound Related Complications with Using Interrupted Whole Layer Closure in Peritonitis Patients. J Korean Surg Soc 2008 Oct; 75(4):221-27.

38. Hyman N, Thomas L, Osler T, et al. Anastomotic Leaks After Intestinal Anastomosis: It's Later Than You Think. Ann Surg 2007 February; 245(2): 254-8.
39. Lustosa SA, Matos D, Atallah AN, et al. Stapled versus handsewn methods for colorectal anastomosis surgery: a systematic review of randomized controlled trials. Sao Paulo Med J 2002; 120:132-6.

40. H Van Goor. Consequences and complications of peritoneal adhesions. Colorectal Disease. Volume 9, Issue Supplement s2, pages 25-34, October 2007.

41. Artinyan A, Nunoo-Mensah JW, Balasubramaniam S, et al. Prolonged postoperative ileus-definition, risk factors, and predictors after surgery. World J Surg 2008;32:1495 $-1500$ 